\title{
EXPLORING MALE AND FEMALE VOICES THROUGH EPISTEMIC MODALITY AND EVIDENTIALITY IN SOME MODERN ENGLISH TRAVEL TEXTS ON THE CANARIES
}

\author{
FRANCISCO ALONSO-ALMEIDA ${ }^{1}$ \\ Universidad de Las Palmas de Gran Canaria \\ falonso@dfm.ulpgc.es
}

$M^{a}$ ISABEL GONZALEZ-CRUZ ${ }^{2}$

Universidad de Las Palmas de Gran Canaria

migonzalez@dfm.ulpgc.es

\begin{abstract}
This article describes authorial voice through evidential and epistemic sentential devices in a corpus of $19^{\text {th }}$ and early $20^{\text {th }}$ century travel texts. The corpus contains four works written by female travellers and the other four by men. Therefore, apart from providing a catalogue of the strategies deployed by the authors in order to mark modality and evidentiality, we also report on expected differences in their frequencies of use in relation to the writer's gender. In addition, the interest of this study lies in the fact that, to the best of our knowledge, no research on writer stance has previously been carried out in texts belonging to the genre of travel writing.
\end{abstract}

Key words: evidentiality, modality, travel discourse, gendered discourse features

\section{Introduction}

This paper offers the results of a study of the usage of evidential and epistemic modals in a corpus of eight English texts belonging to the genre of travel writing. In particular, the texts used here were selected from the vast English literature dealing with the Canaries. Four of the books examined were written by men and the other four by women travellers visiting the islands in the $19^{\text {th }}$ and early $20^{\text {th }}$ centuries. The text selection covers a time

\footnotetext{
${ }^{1}$ Dr Francisco Alonso-Almeida is leader of the Research Project "Evidencialidad en un corpus multidisciplinar de artículos científico-técnicos en lengua inglesa", grant FFI 2009-10801 (Spanish Ministry for Science and Innovation and European Regional Development Fund). This grant is hereby gratefully acknowledged. PROEXT grant PR2011-0115 is also acknowledged.

${ }^{2}$ Dr M $\mathrm{M}^{\mathrm{a}}$ Isabel González-Cruz is a member of the Research Project "El viaje a Canarias y sus escrituras II: Catálogo digital de autores y textos", grant FFI FFI2011-25994 (Spanish Ministry for Science and Innovation and European Regional Development Fund). This grant is also hereby gratefully acknowledged. We would also like to thank Prof. Nina Vivanco for the painstaking work of proofreading the last draft of this paper, as well as for her valuable comments and suggestions to improve it.
} 
span of twenty four years, from 1887 to 1911 . What they have in common is that they give us an account of a journey made to some or all of the Canary Islands, as well as information and opinions about what they saw in them. Because travel texts report on and document factual and non-factual aspects concerning the physical world for other people, they are ideal for the study of devices concerning source of information and degrees of commitment at the time.

Our main aim is to explore how writer authority is expressed by the authors' indication of their degree of certainty about what they write, i.e. epistemic modality, and their source of information, i.e. evidentiality. Tangentially this small sample of texts will shed some light on the use of these devices on a gender basis. For the study of these devices, we will follow Nuyts (2001) and Cornillie (2009) for the identification of epistemic modal devices and evidentials, respectively.

Several authors (Alonso-Almeida and Cruz-García 2011; Alonso-Almeida forthcoming-a; Carretero 2002, 2004; Wallace Chafe 1986; Ferrari 2009; HidalgoDowning 2004; Marín-Arrese 2004; Marín-Arrese et al. 2004; Ortega-Barrera and Torres-Ramírez 2010), have studied the expression of either evidentiality, modality or writer stance in an array of different text types, such as computing and medical abstracts and research papers, conversation, academic writing, legal proceedings, editorials and news articles, newspaper discourse, etc. However, to the best of our knowledge, this is the first research focusing on writer stance through modality and evidentiality in a corpus of travel texts. The relationship between modality and evidentiality has been the object of debate for several reasons, which we will describe in our review of the literature while setting our position in the whole debate. This will guide our analyses and discussion of data.

This paper is organised, as follows. First, we offer a review of the literature on evidentiality and epistemic modality. Second, we give the results of the corpus enquiry for sentential evidential and epistemic devices. The discussion and the conclusion follow from the main corpus findings.

\section{Conceptual framework. Approaching stance, modality and evidentiality}

Evidentiality and modality are often considered within the framework of stance. Stance has been described as "the lexical and grammatical expression of attitudes, feelings, judgments, or commitment concerning the propositional content of a message" (Biber and Finegan 1989: 93). For the study of stance we have to adopt the "information perspective of utterances in discourse", since it involves the analysis of "how speakers and writers express their attitudes toward, and sources of, information communicated". Stance includes the "expression of certainty, generalization and actuality" (Biber and Finegan 1988: 1-2). It can be considered as an umbrella term, covering a wide range of functions and marking various speech or writing styles through the usage of a number of adverbial, adjectival, verbal and modal markers. In their study of styles of stance in 
English, Biber and Finegan (1989) identified a set of twelve categories ${ }^{3}$, based on semantic and grammatical criteria, which gave linguistic expression of attitude under two main topics: evidentiality and affect. The former "refers to the speaker's expressed attitudes towards knowledge: towards its reliability, the mode of knowing, and the adequacy of its linguistic expression"; while the latter "involves the expression of a broad range of personal attitudes, including emotions, feelings, moods, and general dispositions" (Biber and Finegan 1989: 93-94). We will see in the following section that evidentiality is not as straightforward a concept as it might seem in the light of some topical contemporary literature, and so our analyses depart from Biber and Finegan's notion in that evidentiality shows no more than the expression of source/mode of information, as described both in Alonso-Almeida (forthcoming-a) and in Adams and Alonso-Almeida (Alonso-Almeida forthcoming-b). Our study however will heavily rely on Marín-Arrese's interpretation of stance markers (Marín-Arrese 2004), although in her case she also includes deontic modality together with epistemic markers and evidentials (Marín-Arrese 2004: 121). For the moment, we do not analyse the role of deontic modality as a stance marker, since we aim at showing how the authors combine two strongly related notions such as evidentiality and epistemic modality both to convince and suggest knowledge without bare impositions of points of view. This study constitutes an approximation to the study of evidentials on historical texts since studies of this type have been largely ignored in the scientific literature on modality.

This said, our methodological procedure for the study of stance follows from MarínArrese (2004) without, however, considering the deontic modality as a stance marker for the time being, as already pointed out. In our paper, our notion of stance is based on "the communication of assessments and value judgements concerning the described situation by appeal to evidence, expression of degree of certainty or likelihood, as well as arguments regarding the necessity or desirability of the situation obtaining" (Biber et al. 1999: 966). Our interpretation of stance refines theirs in that directions of value judgements are unknown, and for the time being we are convinced of the fact that these values are but listeners' interpretations in accordance with particular selections of contextual premises in the act of processing the information given. Thus, we believe, communicating degrees of certainty by means of evidentials might be unintended by the authors.

\subsection{Approaching modality and evidentiality}

In the last decade, considerable discussion has been going on among scholars about these controversial issues. In fact, their interest in the study of both modality and evidentiality, and especially in the analysis of their interrelationship, has grown noticeably. The former is a term used to refer to the classification of propositions on the basis of whether they assert or deny the possibility, impossibility, contingency, or necessity of their content.

\footnotetext{
${ }^{3}$ The twelve categories were: (1) affect markers (adverbs, verbs and adjectives); (2) certainty adverbs; (3) certainty verbs; (4) certainty adjectives; (5) doubt adverbs; (6) doubt verbs; (7) doubt adjectives; (8) hedges; (9) emphatics; (10) possibility modals; (11) necessity modals; (12) predictive modals.
} 
The latter is a semantic category that in many languages - other than the European - is every bit as important as that of tense or voice. The little attention this concept has received so far can be explained by the fact that no European language seems to possess a grammaticalized evidential system. It is only recently, with the increase in the study of linguistic typologies, that a number of scholars have begun to investigate this field, mainly from the perspective of discourse analysis.

The term evidentiality has been broadly defined in Linguistics as the indication of the nature of evidence for a given statement; that is, whether there is evidence or not for the statement and/or what kind of evidence exists. In turn, epistemic modality indicates the speaker's/writer's opinion and beliefs about the possibility, probability and necessity for the propositional content or the state of affairs described to be true or simply feasible.

The relationship between modality and evidentiality emerges from the fact that the speaker's/writer's modal beliefs or ideas must be based on a number of sources of information which can either be explicitly expressed or remain implicit. In other words, in order to evaluate something as possible, probable or necessary, the speaker/writer must have some kind of direct or indirect evidence, which constitutes the basis for his/her judgement. This explains the relationship between evidentiality and epistemic modality, since by explicitly mentioning the source of information we are using, we are determining the degree of certainty and compromise we assign to our utterance. We will show below that this relationship does not always hold, since the expression of source of information does not necessarily imply degrees of certainty and/or authorial commitment, at least from the authors's perspective.

As González-Vázquez (2006: 13) remarks, the term evidentiality was firstly used within linguistics by Boas in a work on the grammar of Kwakiutl published in 1947, and then mentioned again by Lazard in the 50s in his study of the Tibetian language. Although consolidated by Jakobson in 1957, it is not until 1986 that we can find another publication dealing with this issue, namely, Chafe and Nichol's compilation titled Evidentiality: The linguistic coding of epistemology. Later, another descriptive analysis was carried out by Guentchéva (1996), and this was followed much more recently by works like those of Johanson and Utas's (2000) and Aikhenvald's (2004). The appearance of a monographic issue of the prestigious Journal of Pragmatics in 2001 devoted to evidentiality proves that one of the tendencies now is to define this category interlinguistically, rather than focusing on individual languages and their typologies. Likewise, Marín-Arrese's (2004) compilation offers an approach to the concept of evidentiality from the inspiring perspective of discourse analysis.

A brief look at the contemporary literature on evidentiality reveals that the two main overriding and controversial problems underlying the definition of the concept have to do on the one hand, with the adoption of either a broad or a narrow approach in its study, and on the other, with its interrelation with epistemic modality. Apparently, the two concepts seem to be independent, the former merely dealing with the indication of the source of information, while the latter establishes the speaker's/writer's evaluation of the truth of the proposition uttered, as well as their attitude towards and opinions about what they say in terms of possibility, probability and necessity.

A narrow approach to evidentiality strictly considers it to be dealing exclusively with the expression of the sources or means used by the speaker/writer to obtain the information given. In contrast, the broad approach, which seems to be more widely 
accepted, claims that by indicating the source of information the speaker/writer is implicitly suggesting his/her degree of commitment towards the statement. In Kratzer's words (1981) (apud González-Vázquez 2006: 20), "markers for source of knowledge also mark the speaker's certainty". This means that the speaker's/writer's commitment will be determined by the credibility they concede to the source of information their statement is based on. Therefore, according to this view, the author's reference to his/her sources involves a previous evaluation of the credibility of that source. This implies that a modal function is assigned to evidentiality, which in turn comes to be considered as belonging to the domain of epistemic modality. Many works (Ifantidou 2001; Palmer 1986; Sperber and Wilson 1986; Willet 1988) support this claim. In their view, evidential markers are considered to be expressing not only the source of information but also a modal attitude towards whatever is said.

Within this broad approach, the opposite view also exists and holds that it is modality the one that belongs to the domain of evidentiality. From this perspective, authors like Bybee et al. (1994), Anderson (1986), Dendale (2001), Plungian (2001), among others, claim that modality results from some mechanisms to create or receive information the speaker/writer does not really trust. As Plungian (2001: 251) put it, "while an evidential supplement can always be seen in an epistemic marker, the opposite does not always hold: not all evidential markers are modal in that they do not all necessarily imply an epistemic judgement".

Besides these two perspectives, which alternatively tend to integrate one concept within the domain of the other, there is another group of scholars who hold a third position. Thus, authors like De Haan (2005; 1999), Lazard (2001), Aikhenvald (2004) or González-Vázquez $(2000,2006)$ defend the independence of both categories, claiming that evidentiality "deals with the evidence the speaker has for his or her statement", while modality "evaluates the speaker's statement and assigns it a commitment value" (Haan 1999: 98). In agreement with González-Vázquez (2006: 25), we believe in the autonomy of the two categories, even if evidentials are interpreted in terms of authorial commitment by listeners. This interaction or overlapping between the two concepts has also been explained differently. Thus, Carretero (2004: 27) believes in the existence of "a continuum from evidential to epistemic expressions", depending on the relative importance given to the role of the two steps followed by the addresser when expressing either epistemic modality or evidentiality. These two steps, A and B are as follows:

A) Reception of some kind of evidence

B) Drawing inferences based on both this evidence and general world knowledge.

Meanwhile, for Alonso-Almeida (forthcoming-a, forthcoming-b), the reason why epistemic and evidential readings conflate is because epistemicity is considered to be a pragmatic effect rather than the primary function of the strategy selected as potential evidential.

Another rather controversial question considers the very form and nature of evidentials, since for some authors (Aikhenvald 2004; Joseph 2003) in order to be considered as such, this category should be utterly grammaticalized in the language. However, others like Bybee (1985; 1994), Plungian (2001) or González Vázquez (2006) support the validity of the lexical resources to express evidentiality, as long as different languages may employ different mechanisms to express the same meanings. In Plungian's (2001: 251) words "the same semantic elements may have grammatical 
expression in one language and lexical expression in another (and may even have both kinds of expression in a single language)". In fact, many studies have proved that both evidential and modal meanings can be expressed in discourse through a variety of morphological, lexical, syntactic and even prosodic categories (Ferrari 2009).

One way of classifying evidential meanings is into direct and indirect evidentials, depending on whether or not the speaker has been a witness of the events referred to through any of the senses (visual, auditory, tactile, etc...). In turn, indirect evidentials can be of two types: firstly those used when the speaker infers some specific content either because of the observable facts or through logical reasoning; secondly, those which have been transmitted by another person or through folklore, rumours, literature, etc. Following Willet (1988: 57), González-Vázquez (2006: 17) offers the following chart summarizing the basics of the classification of evidentials:

\begin{tabular}{lll}
\hline Direct (sensorial) & Indirect (inferential) & Indirect (transmitted) \\
\hline visual & based on observable & second hand \\
auditory & facts & folklore, literature, \\
other senses & based on logical & rumours \\
(tactile...) & reasoning & hearsay \\
\hline
\end{tabular}

Table 1: A basic classification of evidentials (adapted from González-Vázquez (2006), drawing on Willet (1988)).

As Marín-Arrese et al. (2004: 124) state, English, like Spanish, does not exhibit as much grammaticalization as other languages, when expressing modality and evidentiality. In their words:

Evidentials primarily indicating sources of knowledge involving immediate perception include the following: see, hear, smell, feel, taste, look, sound. The hearsay category of evidentiality includes verbal and non-verbal expressions such as: say, tell, reportedly, allegedly. Evidentials also include expressions indicating speaker/writer's knowledge and beliefs, such as mental state verbs - know, think, believe, suppose, guess and doubt. Indirect inferential sources are signalled by verbal elements, such as: seem, appear, look as if, sound like, gather, deduce, or non-verbal expressions, such as apparently, seemingly, presumably, evidently, obviously. Epistemic modality is expressed by modal verbs - may, might, could, must, will, should, would - and various non-verbal expressions: possibly, probably, certainly, undoubtedly.

Drawing on Marín-Arrese et al. (2004) and Hidalgo-Downing (2004), in our study we will focus on sentential evidential and epistemic strategies: adverbials, that-clauses, and modals.

\section{The texts: A brief description of the corpus}

The corpus that we have used to carry out this research consists of eight travel books, four of them published by female writers, namely, Margaret D'Este (MdE), Florence du Cane (FdC), Frances Latimer (FL), and Olivia M. Stone (OMS), and the other four by the following male authors, Charles Edwardes (ChE), Isaac Latimer (IL), Harold Lee 
(HL) and John Whitford (JW). Each of them offers the author's account of a trip to the islands containing factual information but mostly their opinions and impressions. The complete data of the books which constitute our primary sources are given in the references section. These travel books emerge as a response for the nineteenth century passion for travel and a taste for exotic lands as a result of contemporary nautical improvements. Interest on the Canaries follows from here. The Islands were exotic enough to pay a visit, but they were also relatively near, just 4 or 5 days from the British Isles. They were also renowned for their good climate, excellent for the cure and treatment of respiratory diseases (cf. González-Cruz, 1995, 2012a). All the works under survey follow the pattern which has usually characterised travel writing as a literary genre, namely, first-person narrator; detailed description of the landscapes and atmosphere of the places visited; a good account of the customs, cultural aspects and behaviour of the native dwellers; a parallel exploration of the inner self, and the urge to escape from the unbearable society ties in search for exotic adventure, for an open-air life. González-Cruz and González de la Rosa (2006) added a new item to this list of features: the tendency to use a number of words, sentences and idioms taken from the languages spoken in each area, something that happens to most of the travellers whose texts we analyse here. All these works belong to a wider bibliographical corpus of English texts about the Archipelago that have been published between 1583 and the present. They are valuable documents which we have classified (González-Cruz 2002) typologically into the following categories: tourist guides, studies about the climate and health, travellers' books and diaries, works of fiction, studies of a historical, sociocultural, linguistic or scientific nature. Due to the different lengths of the travel books selected, we decided to use for our investigation only 5000-word passages taken from random chapters of each of the works.

In the chart below, we list our primary sources, classified by author gender and in chronological order, starting with female authors. Then, we will describe briefly each of the texts included in our corpus, in order to provide the necessary framework for our analysis.

\begin{tabular}{|c|c|c|}
\hline \multicolumn{3}{|c|}{ Female authors } \\
\hline Year & Author & Title \\
\hline $\begin{array}{l}1887 \\
1888 \\
1909 \\
1911\end{array}$ & $\begin{array}{l}\text { Olivia M. Stone } \\
\text { Frances Latimer } \\
\text { Margaret D'Este } \\
\text { Florence du Cane }\end{array}$ & $\begin{array}{l}\text { Teneriffe and its six satellites } \\
\text { The English in Canary Isles } \\
\text { In the Canaries with a camera } \\
\text { Canary Islands }\end{array}$ \\
\hline \multicolumn{3}{|c|}{ Male authors } \\
\hline Year & Author & Title \\
\hline 1887 & $\begin{array}{l}\text { Isaac Latimer } \\
\text { Harold Lee }\end{array}$ & $\begin{array}{l}\text { A summer climate in winter. Notes of a } \\
\text { travel in the islands of Teneriffe and Grand } \\
\text { Canary } \\
\text { Madeira \& the Canary Islands. A handbook } \\
\text { for tourists }\end{array}$ \\
\hline $\begin{array}{l}1888 \\
1890\end{array}$ & $\begin{array}{l}\text { Charles Edwardes } \\
\text { John Whitford }\end{array}$ & $\begin{array}{l}\text { Rides \& Studies in the Canary Islands } \\
\text { The Canary Islands as a winter resort }\end{array}$ \\
\hline
\end{tabular}

Table 2. The texts. 
Stone's travel account is a valuable document that marks a historical and bibliographical milestone for the Canarian development of tourism. In fact, the number of visitors to and writers about the islands increased considerably in the immediate aftermath. The impact of this publication is also evidenced by the appearance of an improved and updated onevolume edition, just two years after the first two-volume version came out. Accompanied by her husband, Olivia M. Stone ${ }^{4}$ was one of the first women travellers to go across and write about the seven islands of the Canarian archipelago, where she spent six months. In this book, Stone, who had previously, and also successfully, published Norway in June (1982), offers a thorough description of the history and the living conditions of the islands at that time, combining criticism and loving appreciation of the beauty and natural advantages of the place.

Isaac and Frances Latimer are respectively father and daughter, travelling together from Plymouth to the two main islands of the Canary group, and each offering their own version of the trip and staying in the islands between March and May 1887. Mr Latimer ${ }^{5}$ was the owner and editor of the famous journal "The Western Daily Mercury", and had also been the Major of Plymouth. His book came out first, consisting of the 15 travel chronicles he had been writing and sending to his journal for publication as a series, following a custom he had when travelling. The great success of these chronicles led him to publish them in book format, something he had previously done with his Rambles in Scandinavia (1882). Similarly, one year later his daughter Frances published her own description of the time spent in the islands as well as the places visited, focusing on the English versus the Canarian ways of life.

Margaret D'Este's book is worthy of attention not only for the text itself but also for the magnificent pictures included in it, all taken with her modern camera, as suggested by the title. This author can be considered as a professional women traveller, who had visited, written about and photographed other places, with her camera both in hand and in the titles of her accounts, namely, Through Corsica with a camera (1905) and With a camera in Majorca (1907). Her trip to the Canaries only covers the islands of Tenerife, La Palma and Grand Canary. The author does not conceive her work as a tourist guide; rather, she states that her aim is to describe her personal impressions and experiences after spending six months in the islands. Therefore, and not surprisingly, a lot of criticism can be found throughout the pages.

After visiting Japan, Madeira and Italy, botanist Florence du Cane travels throughout the seven Canary islands with her sister, Ella du Cane, artist and aquarellist, who offers twenty impressive illustrations that complement and enrich the book. In addition to references to the local flora, the text abounds with sociocultural and historical references which vividly colour Florence's descriptions of landscapes and people.

Despite the title, Harold Lee's handbook deals much more in depth with the Canaries than with Madeira, since, according to the author, the latter was much better known by the public than the former. Thus, many details are given about the living conditions, the character and the typical clothing of Canarians, their customs and agricultural produce. Everything that may be of interest to the visitor is commented upon by Lee, who

\footnotetext{
${ }^{4}$ For further information about the life and the work of this author, see González Cruz (forthcoming).

${ }^{5}$ For further information about the life and the work of this author, see González Cruz (2012b).
} 
recommends starting the trip in Grand Canary, and leaving Teneriffe and Madeira for the way back home.

Despite the short visit he paid to the islands of Teneriffe, La Palma and Grand Canary (a total of two months), Charles Edwardes manages to provide a complete description of all the ins and outs of life in the Canaries at that time, showing an awareness of the sociocultural, political and economic realities of the place. He admits having read a number of books dealing with the Canaries before writing his own, thus justifying the inclusion of the term "studies" in his title. The way he combines description of the present with the recalling of historical facts is really admirable. When portraying the various natural landscapes, he resorts to all senses and includes references not only to forms and colours but also to scents and sounds. Equally noteworthy is the style of his descriptive and narrative prose, which helps the writer fulfill his double purpose: to inform and to entertain.

John Whitford's book is the result of his four-month stay in Grand Canary in order to improve his bad health. After recovering from his rheumatic problems, he decided to visit the rest of the islands, and he started writing and sending his impressions and experiences as chronicles to an English provincial newspaper. Because of their success and the increasing interest and demand for information of the readers, Whitford collected, expanded and elaborated the initial articles, giving them book-format and including maps and pictures. This volume constitutes a practical tourist guide, which also offers authorial impressions and a testimony to a historical epoch: the beginnings of the tourist industry in the archipelago.

Finally, we must bear in mind that whenever we approach the travel literature of this period, we must take into account that this type of text tends to be considered as "a massproduced modular type of writing, since the authors of travel books were driven by market demands and a wish to sell as much as by their desire for self-expression." Despite the fact that they were following the conventions of such genres, it is also true that, overall, they were "seeking to achieve 'truth-effect' and create an illusion of authenticity." For this reason, we can't but agree with those scholars who affirm that "nineteenth-century travelogues are hybrid texts that reproduced cultural conventions and pre-conceived ideas from their authors' places of origin just as often as they reconstructed foreign lands and narrated individual experiences." Likewise, we also claim that interdisciplinary tools are needed in order to analyze travel literature (cf. http://www.spanishtravelers.com/instructional-video.html, website for The Spanish Traveler Project at Marquette University).

\section{Results and discussion}

The research process started with a careful reading of the randomly selected texts, all of which had a length of 5,000 words, as stated above, and was interrupted at that point. First, we tagged the texts manually for sentential evidentials and sentential epistemic devices. In a second step, we carried out an electronic search in order to confirm that all the markers had been included in our count. Graph 1 shows the distribution of epistemic and evidentials in our corpus: 


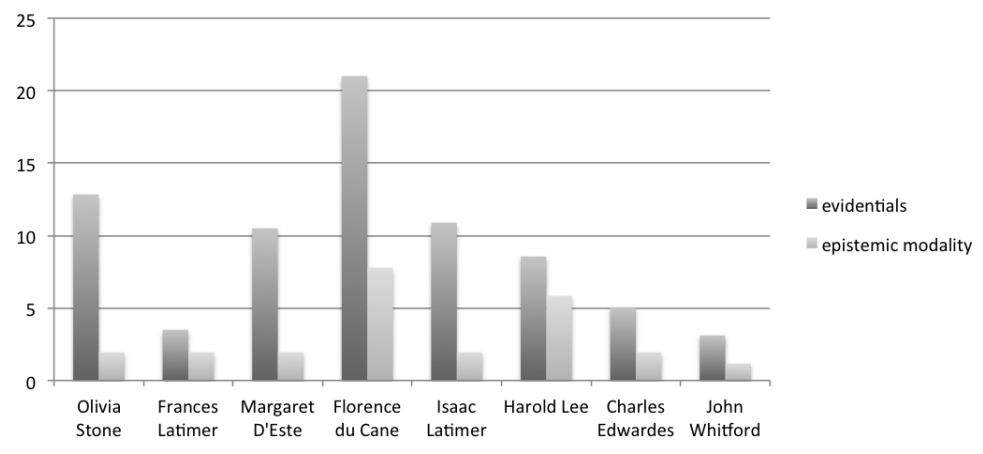

Illustration 1. Evidential and epistemic modality in corpus, frequency of occurrences.

These devices distribute accordingly into the categories of adverbials, that-clauses, toclauses, and modal verbs depending of their attested evidential or epistemic values. In this, we also follow Nuyts's (2001) and Cornillie's (2009) definitions of evidentiality and epistemic modality, respectively, to identify these devices. This analysis reveals the results in chart 1 , below. We will comment on the uses, form and frequencies of these devices in what follows.

\begin{tabular}{|c|c|c|c|c|c|c|c|c|}
\hline & \multicolumn{2}{|c|}{ adverbials } & \multicolumn{2}{|c|}{ that-clauses } & \multicolumn{2}{|c|}{ to-clauses } & \multicolumn{2}{|c|}{ modals } \\
\hline & $\mathrm{V}$ & $\mathrm{P}$ & $\mathrm{V}$ & $\mathrm{P}$ & $\mathrm{V}$ & $\mathrm{P}$ & $\mathrm{V}$ & $\mathrm{P}$ \\
\hline Olivia Stone & 10 & 2 & 14 & 0 & 2 & 0 & 7 & 3 \\
\hline Frances Latimer & 2 & 2 & 4 & 1 & 1 & 0 & 2 & 2 \\
\hline Margaret D'Este & 1 & 3 & 16 & 1 & 7 & 0 & 3 & 1 \\
\hline Florence du Cane & 6 & 12 & 17 & 3 & 27 & 2 & 4 & 3 \\
\hline Isaac Latimer & 6 & 1 & 16 & 0 & 4 & 0 & 2 & 4 \\
\hline Harold Lee & 8 & 4 & 4 & 1 & 2 & 0 & 8 & 10 \\
\hline Charles Edwardes & 3 & 1 & 2 & 2 & 5 & 0 & 3 & 2 \\
\hline John Whitford & 2 & 1 & 3 & 1 & 3 & 0 & 0 & 1 \\
\hline Total & 38 & 26 & 76 & 9 & 51 & 2 & 29 & 26 \\
\hline
\end{tabular}

Table 3. Frequencies ( $V=$ evidential, $P=$ epistemic) 


\subsection{Adverbial devices}

The application of Dunning's log likelihood ${ }^{6}$ reveals that epistemic adverbial stands as more frequent in the case of the texts written by female authors than those written by the male authors. The difference is zero in the case of evidentials, since these appear in the same frequency in the texts written by male and female authors. Adverbials in these texts are deployed in the corpus both as single verbs and prepositional phrases. Evidential adverbials appear in higher frequencies than epistemic ones, and we have found that these two types of devices occur more often in the texts written by female authors. Semantically speaking, there are differences between male and female authorship. Women mainly use epistemic adverbs related to the field of possibility while men tend to opt for adverbs in the realm of probability more frequently. The following instances illustrate this:

(1) Possibly she thinks her best left alone (F. Latimer, 146).

(2) ....and this perhaps afford some clue to the strange ceremony (O. M. Stone, 211).

(3) ...this harbour of refuge will probably be troublesome (Edwardes, 343),

(4) They will most likely turn out a pretty picture (I. Latimer, 86).

In the examples above, the first writer uses an epistemic device such as possibly as a hedging device to mitigate the proposition following. In fact, the adverbial is placed in thematic position to clearly mark that it affects the complete sentence. The second example shows the adverbial perhaps preceding the verb afford to indicate hesitancy as to the author's claim. The examples in (3) and (4) written by men contain examples of adverbials in the realm of probability. These are probably and most likely, which are given in medial position in the sentence. They show a higher degree of certainty of the events to be true than in the case of possibly and perhaps, in (1) and (2) above.

We have classified probably, possibly, and likely as epistemic adverbials on the light of Nuyts's definition of the concept given above. Thus, these adverbials in the examples refer to the chances that the events described may take place or are indeed taking place. However, the motivation for this classification is different in Wierzbicka (2006: 252ff). The author discusses the often alledged relationship between truth and epistemicity to conclude that this connection is "misleading" (Wierzbicka 2006: 252). Wierzbicka claims that interactants cannot possibly relate the use of these adverbs with differing degrees of truth, since that is a task for philosophers. However, their motivation for using these adverbs relies on the speakers's knowledge about the world, and that includes their own thinking. In her description, she explains that probably can be replaced by expressions like I want to say how I think that $P$, I say that $P$, I don't say I know that $P$, I think that $P$. In this line of thought, she argues, I think shows certain

\footnotetext{
${ }^{6}$ Dunning log likelihood functions as chi-square calculation, but it works better in small corpora: "Statistics based on the assumption of normal distribution are invalid in most cases of statistical text analysis unless either enormous corpora are used, or the analysis is restricted to only the very most common words (that is, the ones least likely to be of interest)" (Dunning, 1993: 71).
} 
caution in expressing $\mathrm{P}$, and $I$ say remains as the component of assertion showing casual confidence (Wierzbicka 2006: 267).

In our view, considering these adverbials as epistemic on the grounds that they can be replaced by verbs of thinking and/or verbs of saying means that they can be also classified as evidentials since mode/source of knowledge is clearly manifested. Although we understand Wierzbicka's point with respect to possibly and probably, we still think that the authors exclusively want to convey certain hesitancy concerning their claims, otherwise they would have used an evidential had they wanted to show source of information. Most importantly, listeners would understand a sentence like She will possibly stay longer mainly as an evaluation of chances rather than as a manifestation of the status of knowledge. In this sense, Wierzbicka also states that likely refers to events that are not only "unpredictable" but also "unknowable" (2006: 269). This form is regarded as more subjective than probable and possibly.

As already noted, the Dunning's value concerning the relative distribution of evidentials is zero between the corpus of texts written by men and those by women. In the case of women, the most frequent forms are certainly, no doubt and surely while the most frequent ones in the case of men are evidently, of course and certainly. The following are instaces of all these adverbials:

(5) and [the mountain] would certainly have made a very draughty dwelling (Du Cane, p. 112).

(6) ... and no doubt the green peas and broad beans... often here grow to mammoth proportions (Du Cane, p. 119).

(7) It is then that one gazes awestruck at this world's wonder, a stillness comes o'er the spirit, and we are wafted heavenwards in thought. Surely earthly elevations elevate the mind. They certainly stimulate imagination (Stone, p. 202).

(8) It has evidently been designed not only to do honour to present Las Palmas (Edwardes, 341).

(9) ...certainly if it be carried out into the sun it will show a tendency to jump (Latimer, 83).

(10) Certainly the child is cared for (Lee, 29).

(11) Of course, there are drawbacks in all travel... (Whitford, 5).

The adverb certainly is really common in the two sets of texts written by men and women. The log likelihood is 0.83 with more relative frequency attested in the texts of female authors. The use of this adverbial shows the knowledge of the authors with respect to the propositions accompanied in samples (5), (7), (9) and (10). Quirk et al. (1985: 620) classify certainly as expressing "conviction, either as a direct claim... or as appeal to general perception." In this same group, they categorise the adverbial evidently in (8). This last adverbial seems to be deployed in the example as a certification of truth rather than as the expression of the author's knowledge concerning the proposition. This happens because evidently semantically refers to the idea of clarity and, hence, lack of doubt. Something said to be clear and evident defies testing and verification since there is no need to verify what is obvious. In that sense, the epistemic sense would be undeniable. Notwithstanding, this does not seem to be the sense in (8) and so evidently can be safely replaced by from what I know I say/conclude that $P$ being $\mathrm{P}$ "It has been 
designed not only to do...”. In other words, evidently shows relation neither with truth nor with clarity.

The adverbial surely in (7) frames a speaker's claim, which is also reinforced by the subsequent sentence in the text. The item surely has been defined by Halliday et al. as a device to "express the speaker's judgement regarding the relevance of the message" (1994: 49), thus an epistemic device. Following Haviland (1987), Downing (2001) considers concepts such as truth, reliability, knowledge and authority. In this context, surely is analysed. For Downing, this adverbial is indeed an evidential device, and she identifies three meanings of surely: "surely as a marker of self-validation, surely expressing surprisal or mirative meaning, and surely as a way to foresee and so forearm oneself against foreseen denial" (2001: 257). This view of the function of surely is evidently speaker-based, and rather than showing how information is gained it focuses more on evaluation and reliability of the information, hence an epistemic device. In our example, surely does not seem to be deployed to show evaluation on the status of information. It epitomises both source of knowledge and mode of knowledge. Source of knowledge in the sense that it captures previous information in the text, and mode of knowledge because this previous information leads the author to conclude P, i.e. "earthly elevations elevate the mind".

The case of of course in (11) frames the proposition "there are drawbacks in all travel..." which reports on the speaker's earlier knowledge and so the event described is expected. Listeners or readers may interpret the use of of course as the author's evaluation of the claim in terms of truth. This means that the adverbial seems to communicate factuality of the event. However, as we have already explained, the author uses this adverbial to indicate his knowledge rather than the truth of the proposition. There is no evaluation of the chances of the proposition being true. Similarly, no doubt in (6) relates to the expression of the author's knowledge of the proposition, i.e. "the green peas and broad beans... often here grow to mammoth proportions." The adverbial no doubt implies the result of a cognitive process, and so we can safely substitute the adverbial for the expressions either from my experience $I$ know that $P$ or after observation I conclude P. In many ways, of course and no doubt are stance markers in the sense described in Biber et al. (1999).

Other evidential adverbials identified in the corpus are apparently, undoubtedly, truly, obviously, evidently and presumably, in the case of female writers and surely and indeed, in the case of male writers. The distribution is not significant, as they appear once or twice in the entire corpus. All the cases relate to the expression of authorial knowledge.

\subsection{Evidential matrices and hedges}

Evidential matrices (Alonso-Almeida and Mele-Marrero forthcoming) differ from hedges in that hedges are epistemic devices to mitigate a claim. Hyland (1998: 1) defines the concept, thus: "'Hedging' refers to any linguistic means used to indicate either a) a lack of complete commitment to the truth value of an accompanying proposition, or b) a desire not to express the commitment categorically." Evidential matrices are lexical devices whose primary function is to indicate the speaker's source/mode of knowledge 
and introduce that or to clauses. They constitute the most productive device to show source/mode of information in the corpus. Hedges are not so common as one may think. Log likelihood calculation reveals significant distributional ratio with respect to evidentials, i.e. 114.56. The relative frequency of evidential matrices is 1.27 while the relative frequency of hedges is 0.11 , which indicates overuse of evidential matrices in relation to hedges. The distributional ratio concerning gender is also significant, i.e. 9.08, in the case of evidential matrices in texts written by women with respect to those by men. There is not much difference in the use of hedges in both subcorpora. Comparing the use of hedges and evidential matrices in texts by men, the distributional ratio is noteworthy, 16.93. This is even much more significant in the case of women and that is 43.93. This ratio implies a marked intention of females to show their source/mode of information rather than evaluating and/or mitigating their claims.

The following are examples of evidential matrices in the corpus:

(12) I am told that the indirect influence of the English colony at Las Palmas has done a good deal... (D'Este, 187-8).

(13) ...yet I cannot say the people seemed to be either reverent or deeply religious... (Du Cane, 123).

(14) I conjecture the musician is from the land of Strauss... (Latimer, 149).

(15) ...one would think that some of the many lines of steamers running between England and the archipielago would take one out at a reduced fare (Stone, 204).

(16) [I suggested that the country towns should send news to their capitals that everything was known in the country as soon as it happened], which I suppose, from the habit of the people sitting at their windows, and peering out all day, is very near the truth (I. Latimer, 93).

(17) Now it is evident that even public officials... (Lee, 32).

(18) It appears to be a mixed market... (Whitford, 10).

(19) ....and I was told, when I suggested that the country towns should send news to their capitals that everything was known in the country as soon as it happened (I. Latimer, 93).

Women seem to obtain their information through two main sources. The first one is the result of hearsay and third party attribution. The second one is the result of observation of facts. This last source allows the authors to conclude their information, hence the use of THINKING and SEEM types of verbs. THINKING verbs in the examples above include conjecture, think and suppose. In the case of seem, this form in (13) shows no assessment of chances but a description of facts based on owned or observed knowledge. They are assumptions based on facts but there is no connection with commitment or reliability of the proposition framed. Another frequent group of verbs concerns the SPEAKING type, which very often points towards external non-observed evidence. This also includes the use of passive matrices, as in I am told that in (12).

As seen in Illustration 1, the texts written by men show low figures for evidential matrices. In general, the expression of source of knowledge in these texts comes from their own inferences, thus the use of the THINKING type of verbs as in (16), and from their interaction with other people, and, for that reason, authors deploy verbs of the 
SPEAKING type as in (19). Besides the types of verbs already commented, there are other types as summarized in the following table:

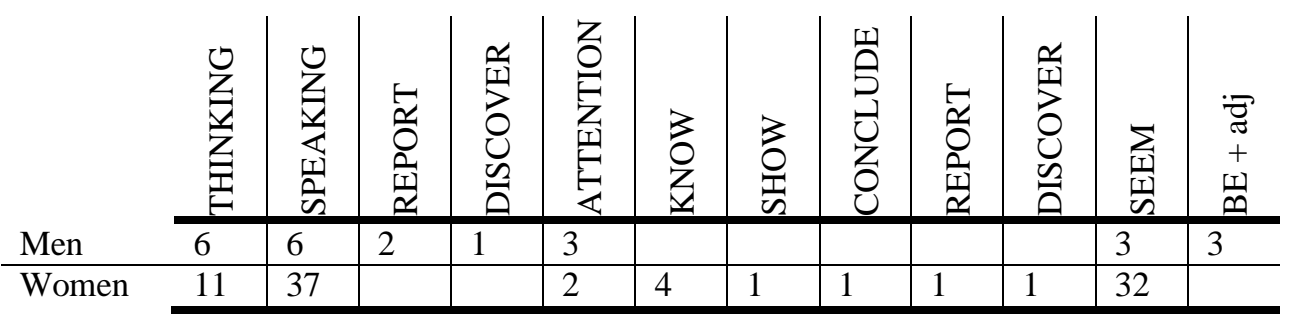

Table 4. Frequencies

An interesting evidential verb is fear which is used both as the main matrix of the sentence in (20) and as a parenthetical in (21), below:

(20) ....and it is feared that so little care is taken... that the disease and blight ...will soon attack these (Du Cane, 110).

(21) $\ldots$ and another one is ill and, it is feared, dying (Stone, p. 210).

In (20), besides the manifestation of information source, the verb fear indicates the author's concern towards the realization of the event framed, ie. "the disease and blight ...will soon attack these". However, in this particular case, the realization of P depends on the fulfilment of the condition expressed by "so little care is taken". In this context, "it is feared" is seen as an intersubjective device, in which the experiencer or conceptualiser is absent, at least, from the surface structure of the sentence. Thus, "it is feared" introduces generalised shared information, which means a less subjective type of stance.

In contrast with evidential matrices, hedges provide an evalution of the proposition they accompany. As already said above, the ratio of hedges in the corpus is relatively low if compared with the evidential matrices. One case of hedging is exemplified in (22), below:

(22) Earlier in the winter it is true the creepers will have been at their best, and by now the last trumpet-shaped blooms will have fallen from that most gorgeous of all creepers, Bignonia venusta, and the colour will have faded from the bougainvilleas... (Du Cane, 120).

In (22), the author shows her point of view with respect to the $\mathrm{P}$ by using the hedge "it is true...", in which she makes clear her position towards the truth of the claim, as if showing her commitment with her text. However, she opts for using the matrix it is + adjective, and that also leaves the experiencer outside the scope of the claim, and so the author cannot really be held responsible for it. 


\subsection{Modals}

Table 5 below shows the occurrences of modals with an evidential or an epistemic meaning. Although evidentials and epistemic modals tend to appear more frequently in texts written by women, it really stands out the use of epistemic may in men in contrast with women, who basically show the same number of modal occurrences with epistemic or evidential nuances. The use of will with an evidential value in texts by women is also noteworthy. We have detected and identified the meanings of these modals by carefully dissecting the contexts where they appear. We rely, as before, on Nuyts's (2001) and Cornillie's (2009) concepts of epistemic modality and evidentiality, respectively.

\begin{tabular}{|c|c|c|c|c|c|c|c|c|c|c|}
\hline \multirow[b]{3}{*}{ evidential } & \multicolumn{2}{|c|}{ may } & \multicolumn{2}{|c|}{ might } & \multicolumn{2}{|c|}{ must } & \multicolumn{2}{|c|}{ will } & \multicolumn{2}{|c|}{ would } \\
\hline & $\mathrm{M}$ & $\mathrm{F}$ & & $\mathrm{F}$ & & $\mathrm{F}$ & $\mathrm{M}$ & $\mathrm{F}$ & & $\mathrm{F}$ \\
\hline & 5 & 6 & 0 & 3 & 7 & 8 & 0 & 2 & 1 & 2 \\
\hline epistemic & 13 & 5 & 3 & 1 & 1 & 0 & 0 & 0 & 0 & 3 \\
\hline
\end{tabular}

Table 5. Occurrences of modals in corpus ( $M=$ male, $F=$ female).

The following are examples of modals with an evidential meaning:

(23) However, this may have been with regard to the homes of the Atalayans, we met with nothing but neatness and cleanliness (D'Este, 200).

(24) By now the last trumpet-shaped blooms will have fallen from that most gorgeous of all creepers, Bignonia venusta (Du Cane, 120).

(25) ...the barranco turning into a lively stream, and we might be again in rural England (F. Latimer, 141).

(26) It must have cost a great deal of money (I. Latimer, 83).

(27) These may have a cooling effect in hot weather (Lee, 30-31)

The use of may with an evidential meaning has been earlier reported in Alonso-Almeida and Cruz-García (2011), and Alonso-Almeida (forthcoming-b). In (23) and (27), may shows inferential reasoning, and it matches with the definition of epistemic necessity in the fashion of inferential must (van der Auwera and Plungian 1998) in many respects. The use of may as an evidential indicates the conclusion speakers arrive at in the light of the contextual premises selected at the time of speaking. In both cases, the experiencers are not included in the statements, and so the speakers are detached from the propositional content. Scholars (cf. Aijmer 2004) see this as a sign of intersubjectivity that, in turn, increases reliability in the information given. In our view, may is not intended to convey authorial commitment and reliability, but mode of information. In our view, the relationship between (inter)subjectivity, reliability and truth is sometimes overestimated since the truth of the proposition is the truth of the speaker with the methodological implications this brings about. In the same fashion, might as in (25) shows information gained as a conclusion of the author's inference. In fact, the modal verb can be replaced by the perceptual verb seem with clear evidential overtones revealing the author's impression: we seem to be again in rural England. Finally in this 
set of examples, must in (26) shows epistemic necessity and so information concerning the excessive cost of the object is inferentially obtained.

Epistemic readings of modals in the corpus are seen in the use of may in the following instances:

(28) The cable at present is not open to the public but anyone may send messages which do not partake of a business character (Stone, 200).

(29) The hills may be steep, but ...every activity on the one side has its corresponding descent on the other (Lee, 33).

These examples of may show the authors's assessment of the chances of the propositions hedged. In (28), the use of may indicates the possibility of people to send cable messages even when the service is not publicly available providing they fulfill the condition that they "do not partake of a business character." An alternative interpretation is to consider the use of may as a dynamic modal. In this sense, may shows the potentiality of the event to take place. However, we opt for the first interpretation in the light of the information given earlier in the sentence, i.e. "the cable at present is not open to the public." In the last instance, the modal shows the judgment of the authors with respect to the steepness of the hills. As it is given, the sentence manifests that the author does not commit himself with the proposition "the hill be steep". In fact, this sentence exemplifies some nuances of authorial stance in the sense that the author does not really seem to bother with the truth of the proposition.

\section{Conclusion}

The most significant contribution of this paper is that there are indeed significant differences between male and female travel writing. In general terms, women tend to use more evidential and epistemic devices than men. Evidential devices are even more frequent than epistemic in the case of women for reasons other than showing commitment. The expression of commitment shows gradation, and this is conveniently expressed by means of adverbials, for instance. The semantic types of adverbials are differently deployed in men and women. While men use adverbs in the realm of probability more frequently, women use epistemic adverbs in the field of possibility. This clearly indicates that women appear to be less assertive than men in terms of adverbials. Evidential adverbials are used in virtually even numbers in texts by both sexes.

In the case of evidential matrices, women tend to use these devices in higher frequencies than men, whose texts present low figures of these evidentials. This indicates the female preference to show how they have gained their information rather than to show their commitment with the truth of the propositional contents. Apart from frequency, another characteristic feature of female writing is the massive use of the SEEM type of verbs to frame descriptions of facts based on observed or owned knowledge. The use of epistemic matrices in the corpus is noteworthy. These matrices indicate subjective authorial stance concerning the information given, and they are often realized by means of the copula be followed by evaluative adjectives, such as true. 
In the case of modals, the major difference between men and women is the massive use of epistemic modality in texts by men, especially the form may. Female writing exhibits again more evidential modals than male writing, which includes instances of may, might, must, will and would. In the case of men, they tend to use almost exclusively the form may with an evidential meaning. The use of evidential may in this period of English confirms our assumptions that may competes with evidential must in formal prose such as academic writing to show inferentiality and epistemic necessity.

All said, we have demonstrated that the characterization of female and male voices can be performed in terms of evidentiality and epistemic modality. Male prose presents less saturation of evidential and epistemic strategies than female prose. The frequent use of evidential devices by women may pragmatically suggest that the authors seek to indicate authority, but also to mark a professional attitude, since the way in which they describe facts can be easily tracked and tested by readers. Men seem not to be in the need of constantly showing their authority as much as women. Epistemic modality does not give strong significant conclusions to allow a clear characterization of gendered writing. Despite this, women admittedly use more epistemic modals than men. This may be indicative of a desire to avoid criticism, but it can be also considered as politeness strategy to avoid the imposition of their claims.

\section{References}

\section{Primary sources}

D'Este, Margaret. 1909. In the Canaries with a Camera. London: Methuen and Co. du Cane, Florence. 1911. Canary Islands. London: Adam and Charles Black.

Edwardes, Charles. 1888. Rides and Studies in the Canary Islands. London: T. Fisher Unwin.

Latimer, Isaac. 1887. A Summer Climate in Winter. Notes of a Travel in the Islands of Teneriffe and Grand Canary. Plymouth: Western Daily Mercury.

Latimer, S. Frances. 1888. The English in Canary Isles. Plymouth: Western Daily Mercury.

Lee, Harold. 1887. Madeira and the Canary Islands. A Handbook for Tourists. Liverpool: Lee and Nightingale.

Stone, Olivia M. 1887. Teneriffe and Its Six Satellites. London: Marcus Ward and Co. Lted., 2 vols.

Whitford, John. 1890. The Canary Islands as a Winter Resort. London: Edward Stanford.

\section{Secondary sources}

Aijmer, K. 2004. Seem and evidentiality. Functions of Language 16.1: 63-88.

Aikhenvald, Alexandra Y. 2004. Evidentiality. Oxford: Oxford University Press. 
Alonso-Almeida, Francisco. Forthcoming a. Propositional epistemic and evidential strategies in Spanish and English texts on Computing. In Juan Rafael Zamorano (ed.) Thinking Modally: English and Contrastive Studies on Modality. Newcastle upon Tyne: Cambridge Scholars Publishing.

- Forthcoming b. Sentential evidential adverbs and authorial stance in a corpus of English computing articles, RESLA. Revista española de lingüistica aplicada.

Alonso-Almeida, Francisco and Laura Cruz-García. 2011. The value of may as an evidential and epistemic marker in English medical abstracts. Studia anglica posnaniensia 46.3: 59-73.

Alonso-Almeida, Francisco and Margarita Mele-Marrero. Forthcoming. Stancetaking in seventeenth century prefaces on obstetrics. Journal of Historical Pragmatics.

Anderson, Lloyd B. 1986. Evidentials, paths of change and mental maps: typologically regular asymmetries. In W. Chafe and J. Nichols (eds.) Evidentiality: The Linguistic Coding of Epistemology. New Jersey: Ablex: 273-312.

Biber, Douglas and Edward Finegan. 1988. Adverbial stance types in English. Discourse Processes 11: 1-34.

- 1989. Styles of stance in English: lexical and grammatical marking of evidentiality and affect. Text 9.1: 93-124.

Biber, Douglas, et al. 1999. Longman Grammar of Spoken and Written English. Harlow, Essex: Pearson Education, Ltd.

Boas, Franz. 1947. Kwakiutl grammar, with a glossary of the suffixes Transactions of the American Philosophical Society 37.3: 201-377.

Bybee, Joan. 1985. Morphology. A Study of the Relation between Meaning and Form. Amsterdam: John Benjamins.

Bybee, Joan, Plagiuca, William, and Revere D. Perkins. 1994. The Evolution of Grammar: Tense, Aspect and Modality. Chicago: Chicago University Press.

Carretero, Marta. 2002. The influence of genre and register on epistemic modality in spoken English: a preliminary study. Estudios Ingleses de la Universidad Complutense 10: 11-41.

- 2004. The role of evidentiality and epistemic modality in three English spoken texts from legal proceedings. In Juana I. Marín-Arrese (ed.) Perspectives on Evidentiality and Epistemic Modality. Madrid: Editorial Complutense: 25-62.

Chafe, W. and Nichols, J. (eds.) 1986. Evidentiality: The Linguistic Coding of Epistemology. Norwood, NJ: Ablex.

Chafe, Wallace. 1986. Evidentiality in English conversation and academic writing. In Wallace Chafe and Johanna Nichols (eds.) Evidentiality: The linguistic coding of epistemology. Norwood: Ablex: 261-72.

Cornillie, Bert. 2009. Evidentiality and epistemic modality: on the close relationship of two different categories. Functions of Language 16.1: 44-62.

De Haan, Ferdinand. 2005. Encoding speaker perspective: Evidentials. In Z. Frajzyngier and D. Rood (eds.) Linguistic Diversity and Language Theories. Amsterdam: John Benjamins: 379-97.

Dendale, Patrick. 2001. Introduction: Evidentiality and related notions. Journal of Pragmatics 33.3: 339-48.

Downing, Angela. 2001. "Surely you knew!" Surely as a marker of evidentiality and stance. Functions of Language 8.2: 253-85. 
Ferrari, L. 2009. Marcadores de modalidad epistémico y evidencial en el análisis de las conclusiones de artículos de investigación de disciplinas distintas, ALED.

González-Cruz, Ma. Isabel. 2002. Notas para una bibliografia inglesa sobre Canarias. La Laguna: Instituto de Estudios Canarios en la Universidad de La Laguna.

- 2012. El viaje de Isaac Latimer (1887) a Canarias: su visión de las islas. In José Manuel Marrero Henríquez, et al. (eds.) La luz no interrumpida. homenaje a Eugenio Padorno. Madrid: Ediciones clásicas: 93-107.

- Forthcoming. Olivia M. Stone y el patrimonio prehispánico grancanario. Frankfurt: Peter Lang.

González-Cruz, Ma. Isabel and González-de la Rosa, Ma. Pilar. 2006. Language and travel: Spanish vocabulary in British travel books. Tesserae. Journal of Iberian and Latin American Studies 12.2-3: 203-17.

González-Vázquez, Mercedes. 2000. La modalidad epistémico subjetiva/objetiva y su interacción con la evidencialidad. In José Oliver-Frade, et al. (eds.) Cien años de investigación semántica, de Michel Breal a la actualidad. Actas del Congreso Internacional de Semántica. La Laguna: Universidad de La Laguna.

- 2006. Las fuentes de la información. Tipología, semántica y pragmática de la evidencialidad. Vigo: Servizo de Publicacións Universidade de Vigo.

Guentchéva, Z. (ed.) 1996. L'énonciation médiatisée, ed. 35 Bibliothèque de l'Information Grammaticale. Louvain-Paris: Peeters.

Haan, Ferdinan De. 1999. Evidentiality and epistemic modality: Setting boundaries. Southwest Journal of Linguistics 18: 83-101.

Haviland, J. B. 1987. Fighting words: Evidential particles, affect and argument. In J. Aske, et al. (eds.) Proceedings of the Thirteenth Annual Meeting of the Berkeley Linguistics Society on Grammar and Cognition. Berkeley, California: 343-54.

Hidalgo-Downing, Laura. 2004. Non-verbal markers of modality and evidentiality and the expression of writer stance in a comparable corpus of editorials and news articles. In Juana I. Marín Arrese (ed.) Perspectives on Evidentiality and Modality. Madrid: Editorial Complutense: 205-28.

Hyland, Ken. 1998. Hedging in Scientific Research Articles. Amsterdam/Philadelphia: John Benjamins.

Ifantidou, Elly. 2001. Evidentials and Relevance. Amsterdam: John Benjamins).

Johanson, Lars and Bo Utas (eds.) 2000. Evidentials: Turkic, Iranian, and Neighbouring Languages. Berlin/New York: Mouton de Gruyter.

Joseph, Brian D. 2003. Evidentials, summation, questions, prospects. In Alexandra Y. Aikhenvald and R. Dixon (eds.) Studies in Evidentiality. Amsterdam: John Benjamins: 307-27.

Kratzer, Angelika. 1981. The notional category of modality. In H. J. Eikmeyer and H. Rieser (eds.) Words, Worlds, and Contexts. New Approaches in Word Semantics. Berlin: Mouton de Gruyter: 38-74.

Lazard, Gilbert. 2001. On the grammaticalization of evidentiality, Journal of Pragmatics, 33.3: 359-68.

Marín Arrese, Juana I. (ed.) 2004. Perspectives on Evidentiality and Modality. Madrid: Editorial complutense. 
Marín-Arrese, Juana I. 2004. Evidential and epistemic qualifications in the discourse of fact and opinion: A comparable corpus study. In Juana I. Marín-Arrese (ed.) Perspectives on Evidentiality and Modality. Madrid: Editorial Complutense: 153184.

Marín-Arrese, Juana I., Laura Hidalgo-Downing, and Silvia Molina-Plaza. 2004. Evidential, epistemic and deontic modality in English and Spanish: The expression of writer stance in newspaper discourse. In Roberta Facchinetti and Frank Palmer (eds.) English Modality in Perspective. Genre Analysis and contrastive Studies. Frankfurt: Peter Lang: 121-40.

Nuyts, Jan. 2001. Subjectivity as an evidential dimension in epistemic modal expressions. Journal of Pragmatics 33.3: 383-400.

Ortega-Barrera, Ivalla and Amelia Torres-Ramírez. 2010. Estudio sobre los abstracts de artículos de investigación informáticos: evidencialidad y modalidad textual. Revista de lingüistica y lenguas aplicadas 5.1: 141-53.

Palmer, Frank. 1986. Mood and Modality. Cambridge: Cambridge University Press.

Plungian, Vladimir. 2001. The place of evidentiality within the universal grammatical space. Journal of Pragmatics 18.2: 245-73.

Sperber, Dan and Deirdre Wilson. 1986. Relevance: Communication and Cognition. Oxford: Basil Blackwell.

van der Auwera, J. and Vladimir Plungian. 1998. On modality's semantic map. Linguistic Typology 2: 79-124.

Wierzbicka, Anna. 2006. English: Meaning and Culture. Oxford: Oxford University Press.

Willet, Thomas. 1988. A cross-linguistic survey of the grammaticalization of evidentiality. Studies in Language 12.1: 51-96. 